\title{
Erratum to: Holditch Theorem and Steiner Formula for the Planar Hyperbolic Motions
}

\author{
Salim Yüce and Nuri Kuruoğlu
}

Adv. Appl. Clifford Algebras vol. 19 no. 1 (2009), 155-160

DOI 10.1007/s00006-008-0131-6

Unfortunately, the original article was published twice. The first publication was in Adv. Appl. Clifford Algebras, 19 no. 1 (2009), 155-160, the second in Adv. Appl. Clifford Algebras, 20 no. 1 (2010), 195-200. The publisher apologizes for this mistake.

\author{
Salim Yüce \\ Yıldız Technical University \\ Faculty of Arts and Science \\ Department of Mathematics \\ Esenler, 34210, İstanbul \\ Turkey \\ e-mail: sayuce@yildiz.edu.tr \\ Nuri Kuruoğlu \\ University of Bahçeşehir \\ Faculty of Arts and Science \\ Department of Mathematics and Computer Sciences \\ Beşiktaş, 34100, İstanbul \\ Turkey \\ e-mail: kuruoglu@bahcesehir.edu.tr
}

The online version of the original article can be found under doi:10.1007/s00006-008-0131-6. 